Article

\title{
The Voices of Young Carers in Policy and Practice
}

\author{
Daniel Phelps ${ }^{1,2}$ \\ ${ }^{1}$ Research and Knowledge Exchange Centre, University of Winchester, Winchester, SO22 4NR, UK; \\ E-Mail: daniel.phelps@winchester.ac.uk \\ 2 www.youngcarers.info, UK; E-Mail: daniel@youngcarers.info
}

Submitted: 30 March 2017 | Accepted: 5 September 2017 | Published: 26 September 2017

\begin{abstract}
This article presents examples from England of the participation of children with caring responsibilities (young carers) in policy and practice at both local and national levels. The 'voices' of young carers themselves have become more prominent at many levels and in diverse contexts such as through local young carers' fora and through dialogue with decision makers, including social care commissioners and Members of Parliament. This participation has for a number of years in England, been strongly advocated for and facilitated by voluntary sector services in particular. Drawing on a number of practice examples, the article will highlight a range of young carers' participatory activity and the extent to which this is woven into policy development and practice. It will consider the processes and protocols of recruitment and safeguarding and the outcomes of young carers' participation, including the influence of their 'voices' in bringing about real change and the impacts on themselves as individuals. Consideration will be given as to whether the voices of young carers has been truly representative of children and young people with caring responsibilities and where particular attention may need to be focused when listening to their voices. The potential risks of young carers' participation at a practical level will be explored as well as the barriers to participation for young carers and approaches for enhancing their participation.
\end{abstract}

\section{Keywords}

caring; child's voice; involvement; participation; policy; practice; young carers

\section{Issue}

This article is part of the issue "Promoting Children's Participation in Research, Policy and Practice", edited by Jo Aldridge (Loughborough University, UK).

(C) 2017 by the author; licensee Cogitatio (Lisbon, Portugal). This article is licensed under a Creative Commons Attribution 4.0 International License (CC BY).

\section{Introduction}

According to the most recent census (Office for National Statistics, 2011), there are 166,363 'young carers' (aged 5-17) in England. A 'young carer' is the term used for children and young adults who have informal caring responsibilities, often for a family member. Legislation in England (HM Government, 2014a) defines a 'young carer' as a 'person under 18 who provides or intends to provide care for another person'. Young people with caring responsibilities up to the age of 25 are often described as 'young adult carers' (Becker \& Becker, 2008). Early research that first identified children as carers made clear recommendations that children should not have to provide care and that services and support should be in place to fully address the person with care needs to en- sure that children do not have to provide care in families. However, for many children, caring is a reality and continues because caring and additional needs are not disclosed or identified in families or because services are inadequate. As will be highlighted later, a preventative and whole family approach (which is now embedded within legislation in England), is needed to support children and families. Such an approach however is not always apparent as evidence shows (Aldridge, Clay, Connors, Day, \& Gkiza, 2016; Children's Commissioner for England, 2016).

Young carers may undertake a wide range of caring responsibilities including emotional support, practical tasks, personal care and household management. Although research has found some positive impacts of being a young carer including children's knowledge and understanding; maturity; life, care-related and social skills 
(e.g., Dearden \& Becker, 2000); allaying fears in children and consolidating parent-child relationships (e.g., Aldridge \& Becker, 2003), evidence strongly points to a range of negative impacts on a child's health and wellbeing, and education (e.g., Aldridge \& Becker, 2003; Aldridge et al., 2016; Dearden \& Becker, 2004; The Children's Society, 2013).

Frank and Mclarnon (2008, p. 57) proposed that "young carers and their families are experts on their own lives and as such must be fully informed and involved in the development and delivery of support services." Young carers are certainly knowledgeable about, and understand better than most, their own caring roles, their own family situations and the needs of the person they care for. Their individual voices about their own situations, as well as their corporate voice are therefore both valid and crucial. Phelps (2012) asserts that it makes sense to involve young carers and their families in planning and designing services, and that this is likely to lead to improved and long lasting outcomes. Phelps also proposes that it should be possible for local authorities to recognise young carer participation as 'core business' and to allocate to it sufficient resource.

Over the last twenty years in the UK, there has been significant primary research with young carers and young adult carers, as there has been in other countries. A vibrant charity sector, or 'third sector', has also become established in the UK, supporting young carers through young carer 'projects' or services. This includes several national organisations that seek to develop policy and practice, support young carers directly and campaign on their behalf. Young carer services, originally developed in response to early research (e.g., Aldridge \& Becker, 1993), have played a significant role in shaping their own models of practice, by listening and responding to the voices of young carers. They have also provided a platform for the voices of young carers at a national level. Through informal research methods such as online questionnaires, focus groups, feedback forms, the collation of views at workshops and larger events, extensive data from young carers across the UK has been accumulated which has complemented and generally confirmed findings from academic research, as well as illuminating potential areas for further research. Moreover, close links between research establishments and third sector organisations, who have often been gatekeepers to young carers, have been a catalyst for change.

In recent years, young carers have become increasingly involved with participatory activity at a national level. Young carers for example, have supported the training for the Department of Health of 'School Nurse Young Carer Champions', they have had opportunities to influence strategic leaders and policy makers through the NHS (n.d.) 'Commitment to Carers' and have fed into the government consultation for the carers strategy.

This article will initially set out some of the participatory practice that has taken place particularly through the third sector in England and how this has benefited, practice, policy and young carers themselves. It then explores safeguarding and recruitment and how this relates to young carers, before discussing key issues around the participatory rights of young carers and their best interests, barriers to participation and improving engagement and whether the voices of young carers have been representative.

\section{Examples of Participation in Practice}

\subsection{The Young Carers Festival}

The Young Carers Festival in England has for seventeen years been an important driver of participation of young carers nationally. The Festival is run annually by a leading national charity, The Children's Society that works to improve policy and practice for young carers and families, in partnership with the YMCA Fairthorne Manor Group and attracts around 2000 young carers from around the country. The voices of young carers have played a central role in guiding the direction of the festival and in steering the policy work of its organisers.

From its onset, the 'Voice Zone' marquee has been integral to the festival and is where participative and consultative activities take place. Activities cover a wide number of themes and have fed into key national consultations and reviews. The festival hosts many high profile MPs and decision makers, including the Children's Commissioner for England and Government Ministers who have come to speak with young carers, take part in 'question time' events where young carers pose the questions, and participate in TV and radio shows broadcast from the festival.

\subsection{The National Young Carers Forum (NYCF)}

In 2007, funded by the Department for Education, The Children's Society in partnership with another leading national charity supporting young carers, the former Princess Royal Trust for Carers, (now Carers Trust), ran the 'Include Partnership' programme of work across England. This four year programme aimed to support local authorities develop their own capacity to support young carers and families. It included training for professionals from education, health and social care, and was responding to the call from young carers for social workers and teachers to be trained, so that they would be better understood and supported.

The first NYCF, composed of young carers from twelve young carer services was established. Services were selected from urban and rural areas and young carers from these services were selected to reflect diversity across the country. Forum members were targeted from a range of different backgrounds including black and ethnic minority groups, those caring for parents with mental illness, substance misuse, physical and sensory disability and those caring for siblings. The Forum informed and played an integral role in the programme. Young car- 
ers presented at conferences and participated in training and consultative events for professionals from education, social care and health, where they told their stories and took part in discussions.

A series of 'residentials' were run at youth activity centres, each with a balanced and diverse itinerary, combining participation and consultation, with fun activities, such as climbing and abseiling. Young carers were interviewed at the first residential and a DVD, 'Listening to Young Carers' (LaunchPad Productions, 2007), was developed out of these interviews. This was used extensively to help train professionals across England, so they would hear first-hand, the experiences of young carers.

This use of media, to chronicle and showcase the participative activities of young carers, is common practice and one with which many young people are comfortable with and consent to. Moreover, filming, interviewing, or forms of social media, such as blogging or vlogging, that yield an end product, may well for this 'social media generation', be almost a necessary requirement and one which paradoxically may help to take the focus off young carers themselves and provide what many may view as a 'legitimate vehicle' to share their personal experiences. Using media can help create a collaborative focus and develop teamwork, whilst the development of an end product such as a film, is something that young carers can feel proud to have been involved in creating. Subsequent residentials focused on developing skills to support young carers in their participatory roles and included workshops to develop media and public speaking skills. Towards the end of the funded programme, a final residential celebrated the Forum's achievements and focused on developing a guide and poster, to inspire local services to establish their own fora and drive change at a local level.

\subsection{The Young Carers in Focus Programme}

The Young Carers in Focus (YCiF) programme, led by the charity The Children's Society, and partners, was a fouryear programme enabling young carers to share their experiences and advocate for change both locally and nationally. A national network was established of around 180 young carer 'Champions' aged 10-25, who received training in media, leadership skills, public speaking and interviewing techniques. The 'Champions' participated in an extensive programme of participatory activities, which included meeting politicians and the Children's Commissioner for England. They participated in national conferences, supported professionals' training, shared their experiences on local and national TV and radio, and took part in a range of consultative activities. Some young carers, were also recruited to the role of 'Champion Evaluators', to support the evaluation of the project (Fleming, 2016).

One legacy of the programme was the development of an 'Influencing Change Toolkit' to support other young carers to influence change themselves at a local level. As with the previously mentioned resources developed by the former NYCF, practical tools like this are valuable in drawing together acquired knowledge, promoting practice and supporting organisations to initiate and develop their own participatory initiatives.

\subsection{A Local Young Carers Forum}

Many young carer services have established a young carer forum to represent the views for their local service. One example is a well-established forum in Norfolk, England which aims to influence policy and practice at a county-wide level as well as national level through its involvement with politicians and development of innovative practice. Within the county of Norfolk, around eleven separate providers deliver a range of services for young carers. In partnership, these providers have formed 'The Norfolk Young Carers Forum', coordinated by the lead service, Carers Trust Norfolk and funded by the Big Lottery which gives grants to organisations in the UK to help improve their communities.

The Forum is composed of three area-wide fora and a county-level forum and gives young carers a 'voice' to raise awareness of issues affecting them and to influence policy and practice within the county. Young carers themselves play a leading role in setting priorities for the Forum, such as improving awareness of young carers within schools. Staff then work with the young people to develop an action plan that addresses these priorities. Care is taken not to impose actions on the young carers, but to allow them to determine their own involvement according to their individual comfort level, strengths and interests. The Forum has previously run large awareness raising events, including one 'question time' event with the then, Minister of State for Care and Support. It has also been involved with the council's commissioning process where Forum members were consulted before a service delivery specification was drawn up and were subsequently involved in the scrutiny process of tender submissions (Phelps, 2012, pp. 15, 40).

More recently, having identified awareness raising in education as a priority, the Forum decided to run an event to coincide with the annual National Young Carers Awareness Day in the UK. Young carers were heavily involved in the event planning, delivering and administration. They drew up the invitation list, chose the location and developed the programme. At the event itself, young carers ran the registration and delivered presentations and activity sessions. They served refreshments, took photos, supported with social media and presented schools with awards for performing well against a set of standards which were designed by the Forum itself.

\subsection{Shaping Grant Programmes}

Since 2009 Carers Trust has been involving young carers in the grant making progress, and the development, design and delivery of specific grant programmes that it runs for individual carers and for carer services. Although 
their substantive role is to review and assess funding applications, young carers have taken on the name of 'Programme Guiders' to reflect the holistic nature of their role and how their decisions help shape the grant programmes. The Programme Guiders are treated as 'colleagues' and are asked to initially sign a 'contract' that sets out the responsibilities of the role, its expectations and its potential benefits.

Young carers review applications prior to gathering for short residentials to make funding decisions. These residentials are funded through the grant programme budgets and take place across the UK, primarily at activity centres and over weekends or holiday periods. Itineraries follow a similar structure. The first day is set aside for travel, signing up to the group contract and making acquaintances. On day two, young carers share their feedback on applications and assist with the decisions for allocating funding. The final day is dedicated to follow-up actions and assigning these to group members.

\section{The National Young Carers Coalition (NYCC) and Changes to the Law in England}

Between 2012 and 2014, the NYCC, a coalition of national organisations (charities and academic institutions) which work with and on behalf of young carers and their families, campaigned to reform and consolidate the law for young carers in line with reforms for adult carers. The NYCC believed this would be achieved through changes to both adults' and children's law and specifically at that point in time, through the Children and Families Bill and the Care Bill. Coalition members believed that neither of the original bills included the necessary provisions for young carers, particularly with regards to assessment and determining eligibility for services in order to improve the situation for young carers and their families through a 'whole family approach'.

The NYCC carried out significant work including developing briefings for MPs, meeting with government officials and submitting evidence to the Joint Select Committee. Throughout the campaign, the Coalition coordinated the voices of young carers and their supporters and thoroughly involved services and young carers themselves in a variety of ways, including encouraging young carers to write and 'tweet' (on the social media platform Twitter) to their MPs.

During the campaign, and in response to an invitation to attend the Young Carers Festival, the then Minister for Children and Families, sent a video message directed to young carers that set out the Government's intentions to improve support for young Carers and families. In his video message, the Minister stated that he often met and spoke to many young carers who always asked him what the Government could do to help make their lives easier. Moreover, he stated that the Government were keen to ensure that young carers were involved in the work that the Government were doing, and encouraged those attending the festival to have their say.
Shortly after the bills passed through parliament, the NYCC organised a celebration event where young carers met Ministers, MPs and Peers who had supported the campaign. These legislative changes to bring about a 'whole family approach' to assessment and support, were considered an 'historic change' by the Coalition and a journey in which many young carers throughout England had been involved. NYCC members viewed the participation of young carers as essential to the campaign in informing and grounding its messages.

\section{Outcomes and Influence}

Many who facilitate young carers' participation, are quick to cite a range of positive outcomes. Hearing directly from young carers can be both emotive and motivating. Feedback from delegates at events commonly indicates that hearing stories first-hand from young carers is the most informative, motivating, and memorable part of an event. Furthermore, direct involvement by young carers often draws media attention which can magnify the reach of messages emanating from those events or particular activities where they are involved.

Although contributions from young carers regarding legislative changes in England and in other policy/practice developments is hard to measure, the voices of young carers at the very least, have helped shape change over a fifteen to twenty year period and is evidenced from what professionals from third sector organisations who support young carers and their families have said:

Really in terms of getting those messages, that messaging right, it would have looked very different if those voices of the young people haven't been there and it wouldn't have been the right way to go I don't think, so really their voices have been the ones that have influenced the change. (National Young Carers Lead, Third Sector Organisation, personal communication, March 3, 2017)

While it may be difficult to demonstrate the impact of participation in some instances, for other activities it is perhaps more straightforward. The participation of the Programme Guiders for example, has undoubtedly impacted local service delivery, with many hundreds of thousands of pounds worth of funding being steered towards specific local interventions, thus affecting provision directly for several thousand young carers. Without their involvement, funding would still have been allocated, however the process, according to the team managing it, was transformative, "having young carers involved in our process has changed it immensely. It definitely makes me and my whole team feel really confident with the feedback that we're giving to applicants about why the application has or hasn't been funded" (Carers Trust, 2015). Similarly, the Forum Lead in Norfolk described the difference that participation had made as 
'massive' and highlighted an immediate impact of the education event which the Forum had helped deliver. Forum members were invited to present to headteachers to discuss their work and the new accreditation system for schools working with young carers, which the Forum had developed (Young Carers Forum Lead Participation Worker, personal communication, February 9, 2017).

\section{Benefits of Participation for Young Carers}

Young carers are not a homogenous group. They will have their own individual reasons for wishing to participate and they will benefit in different ways. However, there are several common intrinsic benefits of participation that young carers do highlight. Being part of making change happen and doing something of value, appear to be key benefits for young carers and their perception of working for a wider benefit and cause may be empowering for them.

Other commonly expressed benefits are making friends and having fun. One young carer reflected that, "I got to meet loads of new people and because I made lots of new friends from places I've basically never been ever" (Carers Trust, 2015). The social benefits of being involved with others seems to be particularly important to young carers, and being with other young people who also have caring responsibilities may help them to relax and enjoy themselves. The Programme Guiders for example built strong friendships within the group and formed a Facebook group to keep in touch. One young adult carer credited the group and the friends they had made, with empowering them to overcome some challenging personal issues. Additionally, the reinforcement that participation provides, of knowing that they are not alone and finding mutual support, has been beneficial to some. As one young adult carer stated, "Being part of the steering group has given me a real understanding of how many other young adult carers' lives can be altered by something like this. It has shown me that you are never alone, and there are always people in the same situation ready to give the support and friendships needed" (Carers Trust, 2014).

For some young carers, having the opportunity to 'do something different', to have new experiences and learn new skills is beneficial. "I thought it would be quite good experience, like I could get some training and stuff. It's completely different from what l'd ever think of doing" (Carers Trust, 2015). Some young carers, particularly those who have become involved in participatory activity through national organisations, have benefitted from a range of experiences that they would otherwise have been unlikely to have had. Young carers who have been part of a 'Media Panel' for the charity Carers Trust, had the opportunity to visit the BBC studios, while other young carers have met with MPs and Ministers and visited the Houses of Parliament.

Developing the skills of young carers to support their participation is crucial for several reasons. Firstly, this can be empowering for young carers and help to build confidence, something that young carers often state is an important benefit of being part of a young carer project. Secondly, it confers value on the young carer role, their contributions and on the children themselves. Thirdly, it promotes children and young people's right to participation and their ability to contribute effectively; and lastly, the skills the young people develop as a result of their participation are transferable and can be particularly valuable as they progress through education and into the workplace. Providing certificates of involvement, online badges, letters of recognition and other creative ways of capturing and accrediting participation and highlighting skills which have been developed are often valued. Offering rewards in the form of vouchers for example, may also be appropriate in recognition of the time committed to participatory activities, which can be particularly precious to young carers. What is important is that the potential benefits, outcomes and rewards, are clearly and realistically communicated and that young carers themselves are asked about how best to recognise their participation.

The experience of participation for some young carers can be profound and empowering. One former young carer stated that, "actually that whole experience was very life-changing for me... when they found actually that I enjoyed talking about my story and I wanted to make a difference for young carers, actually that very much empowered me and it gave you that confidence that people wanted to hear my story, and actually, it gave me skills that have gone on to serve me in my future career" (retrospective account from Andy, aged 29, personal communication, February 9).

\section{Safeguarding, Ethical Issues and Recruitment}

Although well delivered participation has benefitted young carers, participation has the potential to be damaging, especially where young carers are vulnerable. There have been instances where the appropriateness of young carer involvement has been questioned, for example, where telling their story in public has become distressing and where films involving young carers have not put the interests of the child or family first.

Safeguarding issues must therefore be paramount and clear procedures and protocols need to be in place. Ethical clearance, informed consent from parents and risk assessments are all necessary requirements to ensure the safe and effective participation of children and young people.

The best interests of the child must be the overarching consideration, and attention must be given to the safety and protection of the child, as well as ethical considerations, including confidentiality, the child's willingness to participate, and her situation vis a vis her parents and community. (Laws \& Mann, 2004, p. 5) 
Although services may seek to establish participation for a variety of reasons and to recruit and involve particular young carers, they must uphold their ethical responsibility and the best interests of individuals and families. Firstly, it must be established whether young carers wish to participate and to what degree. Young carers should not be pressured to take part. Many children may not identify or label themselves as carers and as highlighted in Aldridge et al. (2016) they may not wish to disclose their caring responsibilities to others, especially professionals. This may be because of concerns about interventions from social workers or through fear of being bullied. Some young carers will therefore not wish to participate at a level that involves 'going public'. Good practice should inform them that they can withdraw from taking part at any time and that they should not feel obliged to share things that they, or their family, are not comfortable sharing. Opportunities, expectations, guidelines and potential outcomes of participation should be clearly communicated early on, so that young carers can make informed decisions about their involvement.

Specific issues should be considered before involving young carers in participatory activities and it is vital to consider the current circumstances of both the young carer and their family. Caring roles and family situations fluctuate and good judgement by professionals, made in accordance with organisational guidance is required to determine whether the involvement of a young carer and type of involvement, would be detrimental at a particular point in time. Where support workers know young people and their families well, they can act as gatekeepers and make informed decisions about their involvement in consultation with children and families. They can also provide additional safeguards, including acting as a trusted adult for young carers to talk to. Since time is often limited for young carers because of caring responsibilities, services should consider the impact of participation on the time they have available for relaxation and social interaction. Similarly, because attainment and attendance at school can be negatively impacted by caring responsibilities, participatory activities should not further impact on a young carer's schooling. Choosing appropriate times for participation that do not conflict with a young carer's education are important and therefore developing training films for professionals that include the voices of young carers, as developed with the NYCC, will reduce the need for young people to miss their schooling.

\section{Participatory Rights and the Best Interests of Young Carers}

As previously discussed, the participation of young carers in a variety of contexts can benefit both policy and practice, as well as young carers themselves. As also discussed, young carers possess a unique understanding of their own family situations and caring roles and it is therefore crucial that their voices are heard in pol- icy and practice. However, it is at this point that accusations of 'tokenism', 'adultism' or 'ventriloquism' (Ruddick, 2007) could be leveled at the kind of approaches in policy/practice that prioritise children and young people's voices but that are ultimately facilitated and led by adults. Despite the affirmation that young carers offer unique insights into the young carer experience, these experiences need to be understood and evaluated in the context of the law, what is in the 'best interests' of the child and with respect to children's family circumstances. In such instances, professionals whose job it is to assess the needs of young carers (and their families) need to do so through consultation and listening to children and families but at the same time they must also make decisions on behalf of children whose legal status requires adults (professionals) to make decisions about their lives that are in their best interests and also protect them from harm.

In addition, there may be instances where the views or stated wishes of young carers contradict or conflict with their own best interests. For example, some children may want to care for a family member who is ill or disabled to the exclusion of their own personal needs. One study of former young carers for example found that as young people, they had often excluded themselves from social activities (Frank, Tatum, \& Tucker, 1999). Some children choose to miss school to care for a parent, or to undertake what may be regarded as time consuming and inappropriate caring tasks. Government guidance on the other hand sets out that "a local authority should consider how supporting the adult with needs for care and support can prevent the young carer from undertaking excessive or inappropriate care and support responsibilities" (Department for Health, 2017a).

There are also reasons why young carers may not accurately express what they may wish to, or what is in their own best interests. Firstly, young carers may experience a range of complex emotions as a result of their caring responsibilities including guilt and fear (e.g., Aldridge et al., 2016) which could skew their understanding of their situation and prevent them from expressing themselves freely. Secondly, young carers, and in particular younger young carers, may not be clear about their own rights, such as their rights to education and to rest and leisure under the UN Convention on the Rights of the Child (UNCRC).

It is important therefore that the views of young carers with regards to policy and practice are adjudicated wisely. Their voice and influence is vital, but equally, it needs to be filtered through a prism of professional understanding based on legislation and the rights of the child, that protect them from undertaking excessive or inappropriate caring. A perspective in line with the 'Whole Family Approach' (Department for Health, 2017b), should also be maintained, where the voices of young carers, parents and other family members are considered carefully. Consequently, those with responsibility for decisions related to policy and practice need to 
be aware of, and understand the law and its principles, including children's rights, with regard to the needs of young carers.

\section{Removing the Barriers to Participation and Improving Engagement}

There are potentially a range of diverse barriers to the participation of young people (and their participatory rights) which include adult attitudes, intransigence, lack of professional training, and the funding and nature of organisations which might include their formality and internal politics (Cavet \& Sloper, 2004). Whilst these would apply to the participation of young people generally, there are additional barriers to participating fully in practice and in activities that are intended to support them that many young carers are likely to face as a consequence of their caring responsibilities. As discussed, young carers often have greater time constraints than their peers with fewer opportunities to socialise, relax and have fun (e.g., Aldridge \& Becker, 1993). Being mindful of this, and ensuring that social activities are woven into participation and that participative activities are creative and fun, is likely to improve engagement. Lack of transport may also often prevent young carers' participation, so measures to address this should be sought, such as providing transport, using accessible venues and technology. More generally, in order to support engagement, flexibility and the provision of a range of opportunities in which young carers can choose to be involved, should be offered. Not all young carers for example wish to stand up and speak in front of an audience. Some may prefer recording their story, writing an article, or developing supportive resources. What is important is that they are provided with opportunities for inclusion and for their voices to be heard.

The Programme Guiders recruited by Carers Trust were supported throughout by staff from support services. This was considered essential, firstly for safeguarding reasons, but also to support and encourage young carers, especially those with low confidence, or with learning disabilities. This required significant commitment from support staff who like the young people, were also asked to sign a 'contract' that set out their supporting role. Most of the Carers Trust Programme Guiders remained engaged in their role for several years, and although not evidenced, the support they received from support workers and the clear communications that they had been given at an early point which set out the role and the expectations, the guidelines for participation and the potential outcomes of their engagement, may have been important factors that supported this lengthy engagement.

Another factor which organisations should focus on and one that, anecdotally, is often not carried out well, is timely feedback to young carers on the outcomes of their participation, by those organising activities. For example, it is encouraging for young carers to receive feedback about any changes in policy or practice that may have taken place as a direct result of their participation. Where feedback is protracted, this might well be discouraging and therefore well-designed and wellimplemented evaluation processes, with relatively short timescales, are likely to improve the motivation of young carers and their engagement.

\section{A Representative Voice?}

Despite commonalities in viewpoint, the voice of one young carer or group is unlikely to represent the views of all young carers. It is important therefore that the voices of certain young carers do not eclipse those of others, nor represent young carers whose opportunities to be heard are limited, or who have no voice. The voices we have heard to date are primarily from young carers who have been identified and who are accessing support from a dedicated young carer service, and despite efforts to work with young carers from particular backgrounds that may make them 'harder to reach', many young carers remain unidentified, unassessed and are not accessing this dedicated support (Children's Commissioner for England, 2016). It is possible that the 'voices' we have heard are different from the 'voices' of those children with caring responsibilities who are not formally recognised or supported as young carers, and who do not self-identify with the term 'young carer' (see Aldridge et al., 2016). For example, what we do know is that the 'voices' of young carers who have contributed their views in research and practice settings to date have often highlighted the value of young carer services, and called for these to be better funded (Aldridge et al., 2016). This is something that children with caring roles, who do not self-identify as young carers, are unlikely to call for.

However, the voices we have heard from have also expressed a need for early identification of young carers by school staff and GPs. Moreover, the importance of 'whole family support' and specifically the need for adequate support for the person with care needs (e.g., Aldridge et al., 2016; Moore \& McArthur, 2007), has been consistently highlighted and has fed into the 'whole family approach' narrative. This principle now lies within legislation and puts more focus on prevention and the need to recognise that young carers are children first (HM Government, 2014a, 2014b; see also Aldridge, 2017). The nature of these needs as highlighted by young carers themselves is likely to be more universal as well as representative of those young carers yet to be identified and supported, and this is also evidenced in research studies both in the UK and elsewhere.

There is however, undoubtedly a need for the other voice-the voice of children not formally recognised as carers - to be elicited further and amplified. Ensuring that these children are heard from, will likely however bring further challenges. As stated by Aldridge et al. (2016, p. 15) "historically, researchers have experienced challenges in engaging with children and families where 
'hidden' young caring is taking place". These children may be found within particular cultural communities or be caring for relatives with perceived stigmatised conditions and where there is fear of disclosing the caring situation because of social care intervention, or where caring is perceived as "normal" (Aldridge et al., 2016). As Kennan et al. (2011) also point out, trying to access hard to reach populations of children can lead to significant ethical, as well as methodological challenges, including having to navigate two layers of gatekeepers, both parents and professionals. Children who have caring responsibilities who have not yet been recognised as 'young carers', are likely to be 'hidden' as discussed and may not wish to be identified, and so finding these children in the first place may require considerable efforts. This was the case in the study in Ireland where successful recruitment was only achieved through perseverance and through raising the awareness of young carers and the importance of the research with gatekeepers (Kennan et al., 2011). As Phelps (2012, p. 15) suggests, "in order to hear what these young people are saying about their needs and current services, commissioners will need to take both a proactive and creative approach and seek to gather views from young people through other routes such as schools, youth services, health and social care settings". This was the approach taken in Ireland and is also being employed in Norfolk where it had been noted that those caring because of mental health or substance misuse issues, were 'vastly underrepresented' in their participation work. To address this, the Forum in Norfolk is looking to partner with dedicated services, such as substance misuse services, who are working with those young people who have not been identified as, or self-identify as young carers.

\section{Final Reflections}

The Participation of young carers in policy and practice has become very much established at both local and national level in the UK, and is now sometimes conditional within funding specifications. The voices, views and ideas of large numbers of young carers, cumulatively, have formed a large data set that has in general confirmed the findings of academic research on young carers and their families. Consistent messages from young carers themselves, such as the need for their whole family support, have undoubtedly helped shape policy and practice. Practice has clearly shown that young carers can indeed be true collaborators and be involved across the life-span of a piece of work, from its vision to its evaluation. The benefits of participation with young carers needs to be recognised by those developing or commissioning services, as well as those directly facilitating it.

However, it is also vital that the risks and challenges of participation and how they relate to being a young carer are understood, and that young carers may have complex needs and emotions as a result of their caring responsibilities, which could have a bearing on the percep- tion of their situation and their capacity to express themselves effectively. Engagement of young carers is likely to be improved when the professionals who work with them set clear expectations and where participatory activities support their specific needs and their rights.

Areas for future development might include: 1) Developing improved recruitment processes, including guidance and screening tools for the recruitment of young carers in participatory activities; 2) Developing personal plans to maximise their involvement; 3 ) Ensuring participation opportunities continue for young carers as they make the transition into adulthood; and 4) A greater focus on hearing the voices of children and young people who do not identify as young carers and are not accessing dedicated support services to understand their experiences and needs.

Finally, since the political, practice and funding landscapes are never static, listening to children and young people who have caring responsibilities must be embedded and be a continual process, one that is adequately resourced and which is always open to exploring new avenues of thought and revisiting old ones.

\section{Acknowledgements}

This article is based on the author's own experiences as a practitioner working in the voluntary sector with young carers and their families as well as telephone contact with professionals working for young carers in the third sector. The author would like to thank all the professionals who gave their time and shared their experiences as well as the reviewers who provided valuable feedback on earlier versions of this article.

\section{Conflict of Interests}

The author declares no conflict of interests.

\section{References}

Aldridge, J. (2017). Where are we now? Twenty-five years of research, policy and practice on young carers. Critical Social Policy. doi:10.1177/0261018317724525

Aldridge, J., \& Becker, S. (1993). Children who care. Inside the world of young carers. Leicestershire: Department of Social Sciences, Loughborough University.

Aldridge, J., \& Becker, S. (2003). Children who care for parents with mental illness: Perspectives of young carers, parents and professionals. Bristol: The Policy Press.

Aldridge, J., Clay, D., Connors, C., Day, N., \& Gkiza, M. (2016). The lives of young carers in England. TNS BMRB.

Becker, F., \& Becker, S. (2008). Young adult carers in the UK: Experiences, needs and services for carers aged 16-24. The Princess Royal Trust for Carers.

Carers Trust. (2014). Nationwide grants programme aims to transform lives of young adult carers. Retrieved 
from https://carers.org/press-release/nationwidegrants-programme-aims-transform-lives-young-adult -carers

Carers Trust. (2015). Carers Trust-W.I.S.H.N.Y Steering Group (YouTube film). Retrieved from https:// carers.org/press-release/nationwide-grants-program me-aims-transform-lives-young-adult-carers

Cavet, J., \& Sloper, P. (2004), The participation of children and young people in decisions about UK service development. Child: Care, Health and Development, 30, 613-621.

Children's Commissioner for England. (2016). Young carers: The support provided to young carers in England. Retrieved from http://www.childrenscommissioner. gov.uk/publications/support-provided-young-carersengland

Dearden, C., \& Becker, S. (2000). Growing up caring: Vulnerability and transition to adulthood; young carers' experiences. Leicester, UK: Youth Work Press for the Joseph Rowntree Foundation.

Dearden, C., \& Becker, S. (2004). Young carers and education. Carers UK.

Department of Health. (2017a). Care and support statutory guidance, Section 6.71. London: Department of Health.

Department of Health. (2017b). Care and support statutory guidance, Section 6.65. London: Department of Health.

Fleming, J. (2016). Evaluation report of young carers in focus champions: What have we found out? Practical participation. London: The Children's Society.

Frank, J., \& Mclarnon, J. (2008). Young carers, parents and their families: Key principles of practice. Supportive guidance for those who work directly with, or commission services for, young carers and their families. London: The Children's Society.
Frank, J., Tatum, C., \& Tucker, S. (1999). On small shoulders: Learning from the experiences of former carers. London: The Children's Society.

HM Government. (2014a). Children and families act (96: young carers). London: Her Majesty's Stationery Office.

HM Government. (2014b). The care act 2014. London: Her Majesty's Stationery Office.

LaunchPad Productions. (2010). Listening to Young Carers [DVD]. Launchpad Productions.

Laws, S., \& Mann, G. (2004). So you want to involve children in research? A toolkit supporting children's meaningful and ethical participation in research relating to violence against children. Stockholm: Save the Children.

Moore, T., \& McArthur, M. (2007). We're all in it together: Supporting young carers and their families in Australia. Health and Social Care in the Community, 15(6), 561-568.

NHS. (n.d.). The NHS commitment to carers. Retrieved from https://www.england.nhs.uk/blog/lavinia-kell man

Office for National Statistics. (2011). 2011 Census: Digitised boundary data (England and Wales). UK Data Service Census Support. Retrieved from https:// borders.ukdataservice.ac.uk

Phelps, D. (2012). Commissioning services for young carers and their families. Carers Trust.

Ruddick, S. (2007). At the horizons of the subject: Neoliberalism, neo-conservatism and the rights of the child part one: From 'knowing' fetus to 'confused' child. Gender, Place and Culture, 14(5), 513-527.

The Children's Society. (2013). Hidden from view. The experiences of young carers in England. London: The Children's Society.

\section{About the Author}

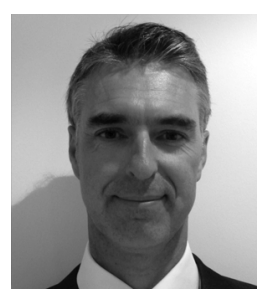

Daniel Phelps worked in the charity sector for 16 years, specialising in policy and practice development for children with caring responsibilities (young carers) and their families. One area of particular focus for Daniel has been improving support for young (and young adult) carers through their education. Daniel was a member of the National Young Carers Coalition. Daniel is now a consultant (www.youngcarers.info) in the field of young carers and a researcher based in the Research and Knowledge Exchange Centre at the University of Winchester. 